\title{
TFIIIB Subunit Gene
}

National Cancer Institute

\section{Source}

National Cancer Institute. TFIIIB Subunit Gene. NCI Thesaurus. Code C20669.

Human TFIIIB Subunit Genes, BDP1, BRF1, and, BRF2, encode protein subunits of RNA Polymerase III Transcription Initiation Factor IIIB, required for RNA polymerase III transcription. Transcription begins with T FIIIC recognition of promoter A and B boxes and TFIIIA, TFIIIB, and RNA polymerase III binding. 90-kDa BRF1 contains a C-terminal HMG2-related region and an N-terminal TFII2B-related sequence. 50-kDa BRF2 has a zinc ribbon domain and a core domain, necessary for complex formation with DNA. Involved in nucleation of a polymerase III initiation complex, BRF2 does not directly bind DNA but interacts with TBP, which binds cooperatively to the promoter. TBP, an essential component of TFIIIB, binds the highly charged C-terminus of BRF1. Highly hydrophilic BDP1 contains a DNA-ligase A1 AT P-dependent binding site and several potential phosphorylation sites. $(\mathrm{NCl})$ 